\title{
Reabilitação de pacientes submetidos à artroplastia total de joelho: revisão de literatura
}

\author{
Rehabilitation of patients submitted to total knee arthroplasty: literature review
}

Flora Ayumi Castello Branco Ioshitake', Daiane Elize Mendes ${ }^{1}$, Mateus Francisco Rossi ${ }^{1}$, Cristiane Delgado Alves Rodrigues ${ }^{1}$

\begin{abstract}
RESUMO
A osteoartrose é uma doença degenerativa comum, em que a articulação do joelho sofre um desgaste de seus componentes, a tíbia, o fêmur, a patela e os meniscos, provocando, assim, um quadro de dor, deformidade e rigidez articular. A artroplastia total de joelho (ATJ) apresenta-se como um tratamento eficaz para os casos mais avançados de osteoartrose. A técnica consiste na substituição dos componentes danificados da articulação por próteses inorgânicas, constituídas de bases metálicas e polietileno. A fisioterapia no paciente pós-ATJ tem a finalidade de restabelecer a função articular, melhorando a qualidade de vida e devolvendo a independência funcional ao paciente.

Palavras-chave: artroplastia do joelho; joelho; reabilitação; fisioterapia.
\end{abstract}

\section{ABSTRACT}

Osteoarthritis is a degenerative joint disease, where the knee joint undergoes wear of its components; the tibia, the femur, the patella and the menisci, thus causing a painful condition, deformity and joint stiffness. Total knee arthroplasty (TKA) presents itself as an effective treatment for advanced cases of osteoarthritis. The technique involves replacing the damaged components of the joint inorganic prostheses, made of metal and polyethylene bases. Physical therapy in the post TKA patients, aims to restore joint function, improving the quality of life and functional independence returning to the patient. Keywords: arthroplasty, replacement, knee; knee; rehabilitation; physical therapy specialty.

\section{INTRODUÇÃO}

Os ossos que formam a articulação do joelho são: fêmur, tíbia e patela, estruturas ósseas que formam duas articulações distintas, a femoropatelar e a tibiofemoral; todavia, funcionalmente, essas duas articulações não podem ser sempre consideradas separadamente, pois existe uma relação mecânica entre elas, e são articulações que proporcionam sustentação ao corpo e podem, com o tempo, sofrer grande desgaste e degeneração, sendo assim necessário um procedimento cirúrgico em que se faz a troca da articulação degenerada por uma artificial. ${ }^{1}$ A artroplastia total de joelho (ATJ) é uma técnica que vem sido utilizada desde o final dos anos 1950 e o começo dos anos 1960, a qual visa substituir a articulação do joelho por uma prótese metálica. É dividida, de acordo com os componentes articulares a serem substituídos, em dois tipos: a artroplastia total, em que são substituídos todos os três compartimentos articulares (femorotibial medial, femorotibial lateral e o femoropatelar), e a unicompartimental, em que apenas um dos compartimentos, seja o femorotibial medial, seja o lateral, é substituído. A técnica tem indicação em pacientes com dor intensa e comprometimento das habilidades funcionais, destruição das superfícies articulares do joelho, instabilidade e diminuição de amplitude de movimento e vem ajudando no tratamento da osteoartrose e da artrite reumatoide, melhorando a qualidade de vida, a dor, a incapacidade e a rigidez causadas por essas doenças. ${ }^{2}$

A fisioterapia tem sido de fundamental importância para a reabilitação do pós-cirúrgico da ATJ, principalmente por meio de exercícios passivos, ativos assistidos e ativos. De imediato, faz-se necessário prevenir eventos trombóticos nos membros inferiores, com exercícios de bombeamento de tornozelo, ganhar extensão da articulação do joelho, minimizar o quanto antes o edema, com a crioterapia e a eletroterapia, recuperar a amplitude de movimento completa em todas as movimentações do joelho e retornar a força e o trofismo muscular do membro. Nota-se que a ausência de um tratamento reabilitativo contribui negativamente para o grau de função da articulação do joelho. ${ }^{3}$

${ }^{1}$ Universidade de Sorocaba - Sorocaba (SP), Brasil.

Contato: florayumi8@gmail.com

Recebido em 31/05/2015. Aceito para publicação em 19/06/2015. 


\section{MATERIAIS E MÉTODOS}

Os descritores usados para busca dos artigos foram: modalidades de fisioterapia, artroplastia do joelho, cuidados pós-operatórios e reabilitação. As bases de dados utilizadas foram MEDLINE, SciELO, PubMed, Google Scholar e Portal CAPES, incluindo artigos dos anos de 2000 a 2014 nos idiomas português e inglês.

Foram encontrados 65 artigos com os descritores citados; dentro dos critérios de inclusão e exclusão, 10 foram usados para a revisão. Foram excluídos artigos que não fossem em português ou inglês, que falassem da artroplastia em outra articulação que não a do joelho ou em animais e os artigos que não tivessem correlação direta com o assunto abordado.

\section{DISCUSSÃO}

Salmela et al. $^{3}$ tiveram como objetivo analisar a influência da mobilização passiva contínua para o ganho de amplitude de movimento em pacientes submetidos à ATJ. Ao final do estudo viram que há controvérsias quando se fala da mobilização passiva, variando conforme o tempo de realização do exercício e de quando ele foi iniciado.

Bacarin et al. ${ }^{4}$ fizeram um estudo a respeito da propriocepção, em que se informou que é difícil comparar a propriocepção em joelhos reconstruídos e não reconstruídos com a artroplastia, devido a dor e a atrofia influenciarem nos resultados, mas a maioria dos estudos lidos informou que pela retirada do ligamento cruzado posterior há uma diminuição da propriocepção articular.

No estudo de Horn e Oliveira ${ }^{1}$ foi analisada a qualidade de vida dos pacientes nos períodos pré e pós-cirúrgico da ATJ, aplicando a eles a Escala de Qualidade de Vida Flanagan; entraram no estudo cinco pacientes submetidos à cirurgia que foram entrevistados antes e após 90 dias de acompanhamento fisioterapêutico. Chegou-se à conclusão, ao final do estudo, de que a qualidade de vida nos pacientes aumentou após a cirurgia.

Barbosa et al. $^{5}$ analisaram vários protocolos de reabilitação existentes e fizeram entrevistas com ortopedistas e fisioterapeutas, elaborando, assim, um protocolo de reabilitação único para pós-operatório de ATJ, em que indicaram a importância do gelo imediato após a cirurgia para diminuição de edema e dor e viu-se que é considerada excelente a flexão até $90^{\circ}$ de joelho.

Carvalho Júnior et al. ${ }^{6}$ tiveram como objetivo do trabalho avaliar a amplitude de movimentos (ADM) do joelho após seis meses de pós-operatório de artroplastia total, comparando-a com o seu valor pré-operatório. Foi analisada a amplitude de movimento de 80 artroplastias, com acompanhamento pós-operatório médio de 21,9 meses. Na análise da amplitude de movimento após ATJ, a flexão pré-operatória influenciou de forma significativa a flexão pós-operatória.

Ritze $^{17}$ estudou o desequilíbrio muscular e a qualidade de vida com indivíduos com osteoartrite e artroplastia, de modo que foram comparados dados antropométricos, atividade física diária, amplitude articular de joelho e torque. Verificou-se que indivíduos com ATJ apresentam diminuição de dor e melhora da qualidade de vida com relação aos que possuem osteoartrite.

Daltro et al.$^{8}$ visaram expor a eficiência da Mobilização Passiva Contínua (MPC), aplicada em conjunto ou não com a fisioterapia convencional, no pós-operatório de ATJ, com o objetivo de maximizar o estado funcional do paciente com respeito à mobilidade e às atividades da vida diária e minimizar as complicações pós-operatórias. Os estudos analisados chegam ao resultado de que a MPC é mais uma opção para o processo de reabilitação do paciente submetido à ATJ, porém, quando a técnica de MPC é feita em conjunto com a fisioterapia convencional, mostram melhores resultados em relação à amplitude de movimento (ADM), daí a importância de a MPC ser acompanhada pelo fisioterapeuta.

Santos $^{9}$ traçou um perfil de pacientes submetidos à ATJ que realizaram fisioterapia no pós-operatório, foram analisados 33 prontuários, em que se encontrou a prevalência de pacientes femininos e com a idade média de 60,1 anos tendo como etiologia principal a gonartrose e a cirurgia a artroplastia unilateral; $87,5 \%$ das cirurgias foram sem complicações e o tempo médio de reabilitação foi de 2,6 meses.

Znojek-Tymborowsk et al. ${ }^{10}$ avaliaram os efeitos de diferentes analgésicos sobre a intensidade da dor no período inicial do pós-operatório da ATJ em um total de 87 pacientes e mostraram que houve maior alívio álgico em indivíduos submetidos as anestesias dos tipos espinhal com infiltração preventiva e local dos tecidos moles do que os que receberam anestesia espinal combinada com anestesia de tecido mole periarticular e bloqueio do nervo femoral, isso no primeiro dia de pósoperatório (nos dias seguintes não houve mudança no quadro de dor).

Moreira, ${ }^{11}$ em seu estudo sobre a reabilitação física no pós-operatório da ATJ, quis demonstrar a importância da melhor forma e individualizada de reabilitação nesses pacientes, realizando, assim, um estudo bibliográfico em que observou-se que a artroplastia é muito procurada e que no pós-operatório podem ocorrer casos de trombose, infecções ou embolias pulmonares, o que faz com que a fisioterapia o mais precoce possível no pós-cirúrgico se torne ainda mais importante, atuando na alta hospitalar até a total reabilitação.

A ATJ é uma cirurgia considerada de grande porte e muito invasiva; ainda assim, vem sendo amplamente utilizada na recuperação das funções em indivíduos que, por algum motivo, como portar osteoartrite, osteoartrose, osteonecrose ou doenças autoimunes, tenham a funcionalidade da articulação do joelho comprometida, possibilitando, assim, após a cirurgia, que esses pacientes voltem às suas atividades de vida diária normais, reduzindo a dor, o edema e a incapacidade. Na cirurgia são trocadas 
as superfícies articulares desgastadas por componentes metálicos na articulação do joelho.

O número de pacientes procurando a ATJ está aumentando cada vez mais atualmente e isso vem se dando pelo aumento da longevidade da população e pela prática de atividades físicas dessa faixa etária. Em estudos para traçar um perfil epidemiológico da população submetida à cirurgia foi constatado que a idade média dos pacientes era de 69,1 anos e que $56,7 \%$ eram mulheres. Os indivíduos que realizaram a ATJ apresentaram grande melhora da qualidade de vida. No estudo de Horn foi aplicado o questionário Escala de Qualidade de Vida Flanagan, que abrange bem-estar físico, material, relacionamentos, atividades sociais, desenvolvimento e realização pessoal e recreação; os pacientes do presente estudo foram entrevistados antes e depois da realização da cirurgia: antes da cirurgia, notou-se uma insatisfação grande em todos os aspectos da pesquisa; no pós-operatório, foi visto que em nenhum momento houve uma insatisfação por parte dos pacientes, demonstrando, assim, uma sensível melhora da qualidade de vida. ${ }^{1}$

A ADM é de suma importância para qualquer indivíduo; a do joelho, especificadamente, interfere diretamente na marcha e a cirurgia de ATJ é muito indicada quando o paciente está com limitação da ADM, cabendo ao fisioterapeuta uma melhor recuperação da amplitude no pós-operatório. Em estudo, Carvalho Júnior et al. ${ }^{8}$ analisaram as amplitudes de movimento nos períodos pré e pós-operatório, em que se observou que a medida de flexão e a extensão de joelho no pré-cirúrgico influenciam nessa mesma medida após a intervenção; isso mostra a importância da fisioterapia em um momento pré-operatório, podendo, assim, aumentar essa ADM. Algo que é utilizado após a intervenção cirúrgica é a MPC, que consiste em um aparelho, colocado ainda no leito hospitalar, que faz movimentos contínuos de flexo-extensão de joelho passivamente, podendo passar um dia inteiro nesse movimento, essa técnica pode ser usada também no intuito de diminuir a dor, o edema e os riscos de uma trombose venosa profunda; mas estudos nos mostram que esse recurso só é realmente eficaz quando aplicado imediatamente após a cirurgia e por tempo prolongado dentro do hospital, mostrando também a ineficácia do uso dela após a alta hospitalar.

A reabilitação física em pacientes após a ATJ é de grande importância para a volta desses indivíduos a sua posição na sociedade, por isso a importância da fisioterapia e de protocolos para que essa reabilitação seja o mais rápido e eficaz possível. Essa reabilitação varia de acordo com o tipo de cirurgia e mesmo da resposta de cada paciente, havendo, assim, a necessidade de tratamentos individualizados para cada caso, visando os ganhos e lidando com as complicações que podem acontecer no geral. A fisioterapia tem como objetivos principais a diminuição de dor e edema, o ganho das amplitudes de movimento e o aumento da propriocepção, força muscular e marcha, trazendo de volta esse paciente às praticas de atividades de vida diária. $\mathrm{O}$ que torna difícil a utilização de um protocolo para essa cirurgia é que há poucos estudos sobre esse assunto publicados; em artigos publicados foi necessário conversar com diversos profissionais, tanto de fisioterapia quanto médicos, para a montagem de protocolos. Barbosa et al. ${ }^{5}$ elaboraram um protocolo próprio em que frisaram bastante a utilização da crioterapia para redução de dor e edema e a relação entre grau de flexão do joelho com dor, em que se espera uma maior e mais rápida recuperação do paciente quando ele consegue realizar uma flexão de $90^{\circ}$ de joelho sem nenhuma ou com pouca dor.

Propriocepção é a capacidade de perceber um movimento ou posicionamento articular identificado pelos mecanorreceptores articulares. Em uma população idosa essa propriocepção já está afetada e em indivíduos submetidos ao procedimento da artroplastia pode ser diminuída ainda mais. Mecanorreceptores e ligamentos como o ligamento cruzado posterior, que tem a função de estabilidade prioritariamente, podem ou não ser retirados durante a cirurgia. A preservação do ligamento cruzado posterior pode ajudar na manutenção do sentido proprioceptivo.

\section{CONCLUSÕES}

A ATJ vem sendo amplamente utilizada em pacientes que têm grandes deformidades articulares, algia intensa ou algum outro tipo de doença reumática; apesar de sua ampla utilização, ainda há poucos estudos referentes a essa cirurgia e sua evolução. A reabilitação nesses pacientes é de extrema importância, devendo o indivíduo, ao fim dela, estar apto a voltar, sem nenhuma sequela, ao seu âmbito familiar, social e de trabalho. A cirurgia traz consigo grandes riscos de pós-cirúrgico, por se tratar de um procedimento de grande porte, e cabe a uma equipe multiprofissional evitar cada um deles. A fisioterapia tem grande atuação nesses casos, diminuindo as dores, evitando tromboembolismos, diminuindo edema, ganhando amplitude de movimento, retornando a força muscular e melhorando a função no pós-operatório dos pacientes.

\section{REFERÊNCIAS}

1. Horn C, Oliveira SG. Qualidade de vida pós artroplastia total de joelho. RBCEH Rev Bras Ciênc Envelhec Hum. 2005;57-64.

2. Kisner C. Exercícios terapêuticos: fundamentos e técnicas. $3^{a}$ ed. São Paulo: Manole; 1998.

3. Salmela LFT, Macedo BG, Aguiar CM, Bahia LA. O impacto da movimentação passiva contínua no tratamento de pacientes submetidos à artroplastia total de joelho. Acta Fisiátr. 2003;10(1):21-7.

4. Bacarin TA, Sacco IC, Kageyama ER, Yogi LS. Propriocepção na artroplastia total de joelho em idosos. Rev Fisioter Univ São Paulo. 2004;11(2):96-104. 
5. Barbosa D, Faria ETB, Almeida Neto D. Fisioterapia em artroplastias totais de joelho. In: IX Encontro Latino Americano de Iniciação Científica e V Encontro Latino Americano de Pós-Graduação - Universidade do Vale do Paraíba. São José dos Campos: UNIVAP; 2005.

6. Carvalho Júnior LH, Castro CA, Gonçalves MB, Rodrigues LC, Cunha FV, Lopes FL. Amplitude de movimento após artroplastia total do Joelho. Acta Ortop Bras. 2005;13(5):233-4.

7. Ritzel CH. Desequilíbrio muscular e qualidade de vida em indivíduos com osteoartrite e artroplastia total de joelho [dissertação]. Porto Alegre: UFGRS; 2008.

8. Daltro MC, Melo KK, Leitão WC. Eficácia da mobilização passiva contínua no pós-operatório de pacientes submetidos à artroplastia total de joelho: revisão de literatura. Portal Interfisio [Internet]. 2009 [acesso em 01 mar. 2015]. Disponível em: http://interfisio.com. br/?artigo\&ID=392\&url

9. Santos AC. Perfil epidemiológico dos pacientes submetidos à artroplastia de joelho do serviço de fisioterapia em hospital público de Santo André-SP. ABCS Health Sci. 2013;38(1):2-7.

10. Znojek-Tymborowsk J, Keska R, Paradowski PT, Witonski D. Relevância da infiltração analgésica para o alívio da dor na artroplastia total do joelho. Acta Ortop Bras. 2013;21(5):262-5.

11. Moreira BS. Artroplastia total de joelho e a reabilitação física. Corpus. 2014;10:64-77. 